\title{
Erratum
}

\section{Community-based screening intervention for depression affects suicide rates among middle-aged Japanese adults - ERRATUM}

\section{H. Oyama and T. Sakashita}

https://doi.org/10.1017/S0033291717000204, first published online by Cambridge University Press 14 February 2017

Key words: Community, depression screening, middle-aged adults, suicide prevention, erratum.

In the above article (Oyama, H., \& Sakashita, T. (2017)) a correction was not made to the figure in the Control areas, Pre - implementation, p-yr column of Table 2. The correct figure should read 197030.

\section{Reference}

Oyama H, Sakashita T (2017). Community-based screening intervention for depression affects suicide rates among middle-aged Japanese adults. Psychological Medicine, 1-10. doi:10.1017/S0033291717000204. 